\title{
Hearing Health Programs for Schoolchildren
}

\author{
Adriana Bender Moreira de Lacerda ${ }^{1 *}$ and Lys Maria Allenstein Gondim ${ }^{2}$ \\ ${ }^{1}$ Department of Audiology, Montreal University, Canadá \\ ${ }^{2}$ Department of Otorhinolaryngology, Vale do Itajaí University (UNIVALI), Brazil
}

*Corresponding author: Adriana Bender Moreira de Lacerda, Faculty of Medicine, University of Montreal, Canada.

Received Date: June 08, 2019

Published Date: June 21, 2019

\begin{abstract}
In the past decades, students' health care has become a priority in many countries and, due to high rates of hearing disorders found in this group, epidemiological studies in the area suggest the need of implementation and development of programs which foster health promotion and prevention from hearing disorders among children and adolescents. Students' hearing assessment is one of the population-oriented actions and early prevention-oriented interventions. Hearing assessment is a simple and fast procedure, applied to a great number of subjects, and aims at the early detection of those most likely to suffer from hearing loss, whether due to conductive or sensorineural pathology, and in need of a complete audiological diagnosis. However, it should be pointed that intervention among that group, in the scope of hearing health care, should not be restricted to hearing assessment only. Other aspects, such as guidance and information on hearing care, and the acoustic school environment, must be considered. In this context, the aim is to propose directions for a model of a hearing health program towards school children based on practical experiences, not only clinical but also academic experiences, comprising perspectives for the use of new health care technologies.
\end{abstract}

\section{Introduction}

\section{The significance and magnitude of the problem}

Hearing is fundamental for the development of language. When hearing loss (HL) is present, problems in communicative processes may occur, hindering global cognitive development, learning and interpersonal relationships, thus harming school development and, consequently, the professional performance of the affected population [1-3]. For the World Health Organization (WHO) [4], hearing impairment may bring about social and economic overburden to individuals, family members and society, that is why prevention is essential. Still according to the WHO [5], about $10 \%$ of the population in any countries has some kind of disability, and hearing impairment takes up $1.5 \%$ of that. For the Global Burden of Disease (2005) [6], 278 million individuals around the globe suffer from some kind of moderate to severe hearing impairment in both ears. From that population, $80 \%$ live in developing countries, and about $50 \%$ of the observed hearing impairments can be avoided by prevention, early diagnosis and treatment. In Brazil, for example, studies show rates of hearing loss among students of up to $39.4 \%$ in some cities [7]. In view of such high rates in several Brazilian regions, Hearing Health Programs for Schoolchildren must be implemented as an integrating part of the primary health care.

Hearing Health Programs for Students - Directions

The Hearing Health Programs for Schoolchildren aim to:
1. Foster hearing health promotion and quality of life among the school community.

2. Identify hearing system disorders early, as they may hinder global cognitive development and interpersonal relationships, and they may also cause or justify immediate and future educational difficulties due to the close correlation between hearing impairments and language problems and/or schooling.

The program should feature a continuous flow and must be founded in three axes:

1. School environment.

2. Hearing assessment.

3. Educational interventions.

Ideally, the program should be part of public policies oriented to child and teenager's caring and should be carried out with other student-oriented government programs.

\section{School environment}

By analyzing the school environment, an important risk factor to be considered is the environmental noise. Investigating noise levels in the school setting, in not only an empty classroom, but also when 
teacher and students are carrying out their activities, would enable the analysis between exposure to environmental sound levels and probable vocal, hearing and health disorders, in addition to the likely effects on the school performance among that population [8-13]. The analysis of the environmental noise may bring about collective and individual measures to solve the problem and foster improvements in school settings, making them healthier. Moreover, for a more efficient performance towards health promotion and hearing loss prevention, it is important to know students' profile, taking into consideration their socioeconomical and cultural status, origin, habits and customs of the population, in addition to hearing signs and symptoms. Such information is necessary to carry out effective interventions and meet that population's needs. Therefore, the use of questionnaires or anamnesis is suggested [14].

\section{Hearing assessment}

The Joint Committee on Infant Hearing (1994) [15] described the basic responsibilities to be met by a program of hearing assessment, such as: awareness of the importance of early diagnosis, whenever there is prognosis of hearing loss, especially in the initial grades; careful observation of students, searching for signs of hearing impairment; organization and carry out of a survey on audiometric data, in addition to a program of guidance and follow-up in order to help children with hearing impairment to have the diagnostic screening, the necessary treatment and adaptation to the school environment. It is essential to consider that, nowadays, not only the already established traditional protocols for hearing assessment, but also new technologies (mobile health apps) have been developed and studied for further implementation and practical use of hearing assessment programs among schoolchildren or adults with promising results [16-19].

The access and use of technologies have been widespread worldwide, as well as the generalized use of mobile technology by children and teenagers, thus being essential elements for communication, relationship, learning, and leisure in their lives. Considering and searching for those tools as well as new technologies and approaches, aiming at the practical use of the mobile health care, including in students' hearing assessment, has great potential. Therefore, it is necessary to advance in order to incorporate them to further interventions.

\section{Educational interventions}

Some initiatives have already been developed in several countries $[20,21]$. Currently, it can be pointed preventive educational interventions oriented to hearing health promotion, founded in the behavior related to children and adolescents' attitudes and hearing habits [22-24]. Some educational/preventive interventions have been efficient to change children and adolescents' behavior [2530]. Considerations on the frequent aspects related to hearing, environmental and biological hazards for the development of hearing loss and its prevention are suggested. Moreover, at schools, it can be suggested that teachers address, in their lesson plan, the issue of health promotion and hearing loss prevention. Thus, along the school year, all the school community can be involved.

\section{Final Considerations}

The hearing health program, founded in three axes, broadens its scope and effectiveness. Although it does not carry out the early detection of hearing loss by means of the hearing assessment, it contributes to the promotion of students' hearing health, fostering positive individual and environmental changes, praising the importance of hearing for the quality of life, minimizing risks and creating healthy settings. That may contribute to the improvement of quality of life, in the perspective of students' comprehensive health.

\section{Acknowledgement}

None.

\section{Conflict of Interest}

No conflict of interest.

\section{References}

1. Sacaloski M, Alavarsi E, Gerra RG (2000) Speech therapy at school. São Paulo: Lovise.

2. Pupo AC, Barzagui L (2009) Progressive, mild and unilateral hearing loss: considerations on a Speech-Language Intervention. In: Fernandes FDM, Mendes BCA, Navas ALPGP. Speech Therapy Treaty $2^{\text {nd }}($ edn) São Paulo Roca 15: 138-148.

3. Vieira ABC, Macedo LR, Gonçalves DU (2007) The diagnosis of hearing loss in childhood. Pediatrics São Paulo 29 (1): 43-49.

4. World Health Organization (2001) Hearing AIDS and services for developing countries. Rev Panam Salud Pública 10: 139-142.

5. World Organization of the Salut (2001) Pan American Health Organization. International Classification of Functioning, Disability and Health: CIF Madri: Ministry of Labor and Social Assumptions/General Secretariat of Social Assumptions/Institute of Migrations and Social Services, Madrid.

6. World Health Organization. Global Burden of Disease.

7. Colella Santos MF, Bragato GR, Martins PMF (2009) Dias Ab Auditory screening in schoolchildren aged 5 to 10 years. Rev CEFAC 11(4): 644653.

8. Kristiansen J, Lund SP, Persson R, Shibuya H, Nielsen PM, et al. (2014) A study of classroom acoustics and schoolteachers' noise exposure, voice load and speaking time during teaching, and the effects on vocal and mental fatigue development. International archives of occupational and environmental health 87(8): 851-860.

9. Klatte M, Bergström K, Lachmann T (2013) Does noise affect learning? A short review on noise effects on cognitive performance in children. Front Psychol 4: 578.

10. (2010) ANSI S12.60 American National Standard Acoustical Performance Criteria, Design Requirements, and Guidelines for Schools, Permanent Schools.

11. Dreossi RCF, Momensohn Santos T (2005) Noise and its interference on students in a classroom: literature review. Pro Fono 17 (2): 251-258.

12. Marasca C, Lacerda A (2001) Sound Pressure Levels of Municipal Schools of Itapiranga Santa Catarina. Revista Pró Fono 13 (2): 277-281.

13. Jaroszewski GC, Zeigelboim BS, Lacerda A (2007) School noise and its implication in dictation activity. Revista CEFAC 9 (1): 122-132.

14. Nunes ADS, Silva CRL, Balen SA, Souza DLB, Barbosa IR (2019) Prevalence of hearing impairment and associated factors in adolescents and school-aged children: a systematic review. Braz J Otorhinolaryngol 85 (2): 244-253.

15. Joint Committee on Infant Hearing (1994) Position statement. Audiology today. 
16. Rourke R, Kong DCC, Bromwich M (2016) Tablet Audiometry in Canada's North: A Portable and Efficient Method for Hearing Screening. Otolaryngol Head Neck Surg 155(3): 473-478.

17. Swanepoel DW, Myburgh HC, Howe DM, Mahomed F, Eikelboom RH (2014) Smartphone hearing screening with integrated quality control and data management. Int J Audiol 53(12): 841-849.

18. American Academy of Audiology (2011) Childhood Hearing Screening Guidelines. American Speech Language Hearing Association (1997) Guidelines for Audiologic Screening.

19. Meinke DK, Norris JA, Flynn B, Clavier OH (2017) Going Wireless and Booth-less for Hearing Testing in Industry. Int J Audiol 56(SUP1): 41-51.

20. Dangerous Decibels do Oregon Hearing Research Center.

21. Wise Ears.

22. World Health Organization Billion (2015) People at Risk for Hearing Loss. Geneva, Switzerland: WHO Media Centre.

23. (2019) Toolkit for safe listening devices and systems. Geneva: World Health Organization and International Telecommunication Union.

24. Meinke D, Martin WH (2000) World Health Organization Development of Health Communications for Promotion of Safe Listening: a review?
25. Lacerda ABM, Soares VMN, Goncalves CGO, Lopes FC, Testoni R (2013) Educational workshops as a strategy to promote adolescent auditory health: an exploratory study. Audiology Communication Research 18: 85-92.

26. Soares VNM, Lacerda ABM (2012) Group activities and the juvenile protagonism in the health of the scholar in the field of phono audiology. In: Berberian AP, Santana AP (Eds.), (Orgs) Fonaudiology in group contexts: theoretical and practical references. Curitiba: Plexus pp: 183201.

27. França AG, Lacerda ABM (2014) Auditory health promotion: educational strategies developed by high school students. Communication Disorders 26: 365-372.

28. Knobel KA, Lima MC (2014) Effectiveness of the Brazilian version of the Dangerous Decibels (®) educational program. Int J Audiol 53 Suppl 2: S35-42.

29. Martin WH (2013) Randomized trial of four noise-induced hearing loss and tinnitus prevention interventions for children. Int J Audiol 52 Suppl 1: S41-49.

30. Folmer RL, Griest SE, Martin WH (2002) Hearing conservation education programs for children: a review. J Sch Health 72(2): 51-57. 